\title{
An Analysis Of The Proposed Performance Based Pay System For Academic Staff At The University Of Technology, Jamaica \\ Horace A. Williams, (E-mail: williebo@cwiamica.com), University of Technology, Jamaica Robert C. Preziosi, (E-mail: preziosi@huizeng.nova.edu), Nova Southeastern University
}

\begin{abstract}
This paper discusses the implications for the use of performance based pay practices for academics at the University of Technology, Jamaica. Some universities systems which have attempted performance based pay for academics in the United States. Systems in Canada and United Kingdom were also reviewed. The findings are that the Academic Staff at the University of Technology, Jamaica are inclined to retain the current annual increment payments, union negotiated increases together with implementation of a Performance Based Pay System. This should be based on a properly structured Performance Appraisal System and the establishment of clearly defined objectives.
\end{abstract}

The paper concludes that the future practices will necessitate retaining the increments supported by the Jamaican Ministry of Finance and the implementation of a bonus system structured on the premise of a performance based pay system supported from surplus funds derived from donations, investments funds and endowments to the University.

\section{Introduction}

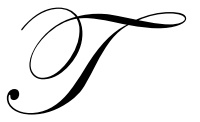

he University of Technology, Jamaica (UTech) was established as a University on September 1, 1995. Prior to this, the institution was a Technical College for thirty-seven (37) years offering diplomas mainly in the Technical and Business areas. There are now five faculties; the Built Environment, Education and Liberal Studies, Engineering and Computing, Business and Management and Health and Applied Sciences. UTech has been patterned after the United Kingdom Polytechnic University System. However, over the past eight (8) years since its formal establishment, there have been several strategic alliances, Memoranda of Understanding, student exchanges, faculty exchanges and joint programmes with North American, United Kingdom, Australian and New Zealand Universities.

The University is a Government supported public education institution that now compensates individuals on the basis of the negotiated salary increases through the collective labour agreement and annual increments. Annual increments has been paid between December 2000 and December 2002. This was so since Performance Based Pay and the Incentive Award System should have been in place since that time, but was not. The source of funds that would form the bases for these payments would be the budgeted amounts from the Ministry of Finance \& Planning, Jamaica for the performance aspect and the incentives would be paid from a portion of the annually generated surplus. The Performance Appraisal would be the mechanism for paying the performance-based aspect. A basic ingredient to this process would be a proper performance appraisal system, a major challenge in the academic setting. 
It has been established that the unions representing the staff affected would want to adhere to the present system of annual increments and the implementation of an incentive award. A culture of a properly administered performance appraisal system has to be developed over time.. The sustainability of the award scheme would be dependent on the Ministry of Finance \& Planning allocation. An incentive scheme, if implemented, would be sustained from generated surplus. Central to the proposal is the University's objective to have an academic staff operating at world-class standards in teaching and research. It has been demonstrated that the Performance Appraisal is the base of any Performance Based Pay (PBP) System and that salary awards made in the context of PBP should direct faculty towards the University's objectives.

The incidence of merit pay plans in Canadian universities reinforces the view that institutions with a greater emphasis upon research relative to teaching, where output is "easier" and less costly to measure, will tend to favour pay-for-performance plans. In contrast, where there is distrust of administrative discretion and pressure from faculty associations for more uniform compensation based upon a definition of satisfactory performance, faculty opposition may lessen the potential productivity gains. Any change in compensation schemes, therefore, is likely to occur slowly and only in the face of significant resistance.

The literature from the United Kingdom shows that some universities operate PBP for senior staff only. However, 65 per cent of pre-1992 universities currently operate a system of PBP for all academic staff, or at least operate systems which are based on elements of academic staff performance. Where "PBP" of some kind is used, there appears to be a big emphasis on individual unconsolidated bonuses derived through forms of peer and colleague assessment (for example, through committees organised in a collegial manner (Hardy, 1991; Rutherford, 1992), staffed by academics and with heads or chairs elected from amongst academic staff).

The movement towards merit-based pay systems in American universities has been described as "slow and painful". It was largely abandoned in the 1930s and 1940s in favour of standard seniority-based increases that were easier to administer. They gained renewed popularity after 1950. Despite the expressions of support for merit pay by some administrators, particularly within business schools (Prewitt, Phillips and Yasin 1991), it is deemed by others as "pestiferous and professionally demoralizing" (Hoko 1988). And while the data on merit pay in American universities is limited, the most exhaustive survey finds a "preponderance of evidence of merit plan failure," largely due to problems of implementation (Taylor, Hunnicutt and Keeffe 1991).

Arguably the need for effective use of human resources in the UK higher education (HE) sector has never been greater, despite the fact that the sector appears to have coped with the pressures of increased student numbers with reduced public funding which became particularly obvious in the early 1990s (Miller, 1994). This stems not only from the general need to do more with less, but also from issues raised by the Dearing Report (1997) and its aftermath, such as the need for greater consistency of teaching standards and improved quality. However, one paper ( Keep, Storey \& Sisson 1996) described a general lack of consistency and integration of personnel management approaches within universities and across the sector as a whole - a shortcoming which seriously threatens to undermine the ability of the sector to deliver quality teaching and research.

Performance Based Pay (PBP) has been described as "the explicit link of financial reward to individual, group or company performance" (Armstrong and Murliss, 1991). It is part of a re-orientation of pay and reward systems away from traditional methods of job evaluation and time-based pay, often carried out on a collective basis to a more individualized approach which recognizes employee contributions. In the UK, this re-orientation is generally seen as a phenomenon of the late 1980s and early 1990s and is associated with changing economic, political and social circumstances and a changed managerial agenda (Kessler, 1994). Although having origins in the private sector, such changes have brought PBP into the public service sector domain (Armstrong, 1996).

Three forms of PBP have been identified by Kessler (1994). First, individual merit and performance-related systems are based on appraisal, making a payment which is consolidated into a basic time-based salary. Second, individual unconsolidated bonuses can be often based on production targets. Third there can be unconsolidated bonuses which are group-derived and collectively paid. Although often assumed to be used as a direct motivator to improve individual employee performance, there are examples of PBP which have played a part in recruitment and 
retention of staff by enabling higher pay levels which are more representative of market rates to be paid over and above collective pay scales and for various cultural and image-making purposes such as the pursuit of a non-union individualistic culture with a reinforced line manager role (Armstrong, 1996). As such, PBP is typically inextricably linked with appraisal, although the potential corruption of developmental appraisal systems by adding a pay link, and the problems of maintaining objectivity in assessment criteria, have been well documented (Kessler, 1994; Randell, 1994).

In the UK Higher Education system national collective bargaining provides a framework of pay scales and ensures some uniformity of practice across the sector, albeit there are different scales for the pre- and post-1992 universities and some other variations such as a London weighting allowance. National collective agreements of a more procedural nature have enabled and in some cases required individual institutions to operate a form of PBP. However, the method of PBP and of payment calculation has been a matter for individual institutions to negotiate and introduce locally. Hence, as an indicator of sectoral uniformity or diversity, PBP is of great interest, and may well assume even more significance if the power of national collective pay bargaining is eroded (Farnham, 1997). The publication of the findings of the Independent Review Committee on pay and conditions for HE staff chaired by Sir Michael Bett made recommendations about implementation on an individual institution basis.

The decline in the general level of pay in the Higher Education System has been documented. (Keep, 1996; Murlis and Hartle, 1996) This placed severe constraints on the levels of PBP payments available. Paradoxically, this also placed greater significance on PBP as a means of providing supplements to basic pay. However, it was noted that individual academics could also supplement earnings by consultancy and other activities, which the current contracts of employment allowed for (Murlis and Hartle, 1996). In the pre-1992 universities, individual PBP was introduced, as a condition of funding by the Department of Education and Science through the UFC in 1989 "explicitly to enable university managements to recruit or retain exceptionally scarce or valuable staff and reward exceptional performance" (Wilson, 1991). The intent was to fulfill two of the purposes of PBP.

Increasingly, universities are being approached to consider the use of profit-related pay. This may be possible where universities do not have direct national or local government control, and the terminology of university purpose indicates that they are "operating with a view to profit" and not "'trading' with a view to profit" (Coopers \& Lybrand, 1996). However, such developments are relatively new especially with the advent of off-shore Universities which must generate a profit to be sustainable.

\section{Literature Review}

Most organisations act on compensation decisions after deciding on what goals are to be accomplished. There are two goals of every compensation system. The first is to elicit behaviour from individual employees for efficient output and the second is to determine where in the market the organization seeks to position itself. (Bergman \& Scarpello 2001) Performance Appraisal is the most challenging area confronting the organization. (Berg, 1976) Employees have to know how they are doing, what they are to do and how they feel about their job. If done properly, performance appraisal is the essential adjunct to productivity. However, it is seldom done well. Top performers have to be rewarded and are demotivated if they do not receive that level of recognition. Quantitative evidence of performance gives the organization a chance to show appreciation for excellent work (Fitz-Enz \& Davidson, 2002).

A key feature of all performance based pay systems is the method of assessing and measuring what has been achieved. This is the challenge facing the implementation of this proposal (Williams, 2001). For the incentive plan to be effective, the university must be able to meet the assumptions of instrumentality, expectancy, and reinforcement. Employees must be capable and believe that they are capable of performing at high levels. They must see that high performance results in more pay or something of value. Also, there must be performance variability potential in jobs and the University must develop fair and equitable systems which measure that variability and provide adequate rewards to reinforce appropriate behaviours. 
Of the various aspects of faculty compensation systems, merit pay has received the most sustained attention. Performance-based salary awards are not new in North American and British universities, but the reception has been decidedly mixed. Designed to motivate and reward greater productivity, they are embraced as a tangible expression of the "university as meritocracy" (OCUFA 1978) and denounced as Reaganomics encroaching upon the academe (Pratt 1988). Johnson (1974) viewed performance-based pay as one avenue for avoiding "the academic vices, evident to the most casual observer of the British, Canadian, and Australian academic scenes, of not working hard enough and of retiring from real work early on the strengths of one early bout of hard work spent on winning a Ph.D. and/or the publication of a promising scientific paper." In contrast, Hamermesh (1988) cautions that: "preventing salary differences from generating feelings of second-class citizenship is essential to maintaining a common purpose among faculty." However, salary equity is not assurance of common purpose.

Similar views were expressed in Canadian universities. Most complaints stemmed from the difficulty in translating the university's objective function into clear, financial signals. A committee at the University of Guelph reported that: "Surveys of the Faculty have repeatedly found that faculty: (a) support merit evaluations and (b) dislike and distrust the present system [due to] variable departmental rating distributions, changing amounts available for distribution, and varying dispersal schemes" (CAUT 1993). Where the evaluation system is unpredictable, or the rules of the game were deemed to be biased, a merit plan would not evoke the correct response from faculty and, indeed, may engender sufficient discontent to be counterproductive. Defining unambiguous measures of faculty performance is a long-standing problem, elegantly expressed by a committee at the University of Alberta. A university evaluation system, to be effective, must avoid both the scylla of encouraging popular instruction (without emphasis on required reflective inquiry) as well as the Charybdis of rewarding only the quantified measure of publication of research to the detriment of both scholarship and teaching (University of Alberta, 1991).

At a national level, the requirement for universities to have something in place which is termed "appraisal" has been the subject of broad national procedural agreement for some years. However, individual institutions have had a high degree of autonomy in specifying the detailed substance of the appraisal system. For the pre-1992 universities, the introduction of a process which could formally be termed "appraisal" was implicit in the recommendations of the United Kingdom Jarratt Report (Committee of Vice Chancellors and Principals, 1985) and was introduced in 1989 as a result of the 1987 salary agreement between AUT and CVCP (Pollitt, 1990). Ultimately, as Bright and Williamson (1995) describe, this formalisation was inevitable as it was the subject of a government imposed condition in order to release budget funding for 1988. The introduction of appraisal into these institutions appeared, according to Rutherford (1988) and Bryman et al. (1994), to have overlain existing informal processes, as predicted by Farnham (1985). The latter author quotes such processes as: the detailed criticism/advice on a draft paper or book from a colleague, an interview with a head of department on some aspect of academic performance, information from a formal discussion with students about a course, and colleague and student feedback on a range of other activities. All of these were in existence at the University of Birmingham in the academic year 1986/87. Rutherford's (1992) and Bright and Williamson's (1995) descriptions of appraisal at Birmingham and Durham universities respectively, together with more general work by Townley (1990), documented the nature of the systems as being very much developmental in orientation. These appraisal methods have been seen as characteristic of a collegial way of working, in the sense that collegial is defined as "the involvement of all academic members of the organisation ... through consultation, as both leaders and led" (Middlehurst and Elton, 1992) and as a process to which participants are willing to contribute necessary time and effort to consensus-building (Hardy, 1991). As such, they may leave as is a particular style of appraisal, which, although introduced in name by national requirements, is culturally-specific to the pre-1992 universities.

These approaches could be contrasted with the post-1992 universities, where appraisal schemes were formally introduced at a later date, but where, following Thorne and Cuthbert (1996), a more managerial approach might have been expected. The 1992/93 funding round required the adoption by former polytechnics of systems of PBP. Bright and Williamson (1995) attributed the introduction of appraisal to this initiative. By making this attribution, implicitly this would seem to have indicated a more managerially-controlled evaluative agenda to appraisal in these institutions. 


\section{The Case Of The University Of Technology, Jamaica}

A Performance Based Pay System as proposed has the potential to create a more productive and creative academic environment if its goals and objectives are clearly understood. Faculty and managers would be expected to know what is expected of them, if expectations are reasonable and mutually agreed upon, and the perception that the decision process is fair and impartial. The University of Technology, Jamaica decided to implement a Performance Based Pay System to compensate individuals who have contributed in significant ways to the growth, development and strategic direction of the University. Performance Based Pay would be paid to faculty who have met and exceeded their objectives and who are appraised at levels satisfactory, commendable and outstanding. Individuals who have been appraised at the levels below these would not benefit from this scheme. These individuals would have been recipients of the annual negotiated increases through the collective labour agreement process and annual pay increments.

The model being proposed would not replace the annual negotiated increase in basic salary through the collective labour agreement process. This proposal is intended to provide a scheme for rewarding faculty for consistently excellent performance in the areas of research, teaching and advisement, service to the University and service to the community. The Performance Appraisal System would be the basis for determining the three levels of performances outstanding, commendable and satisfactory. Areas of assessment would include the following:

- $\quad$ Peer Assessment

- $\quad$ Student Evaluation

- $\quad$ Achievement of Objectives in the areas set by incumbents and respective Deans and Department Heads.

- $\quad$ Service to the community

- $\quad$ Service to the University

Only where appraisals have been professionally done and the University's Policies and Procedures, as they relate to the performance appraisals, are followed would an individual be a recipient of the Performance Based Pay. Overall performance would be measured at three levels - Corporate, Department and Individual. Payments to any individual in the University would, therefore, be based on performance at all three levels.

- $\quad$ Only those employees whose performance would have been appraised as outstanding, commendable or satisfactory during a 12-month period since the last formal annual performance review, would earn a payment.

- $\quad \underline{\text { In addition }} \underline{\text { to }}$ receiving his/her negotiated basic salary increase as per the Collective Agreement, an outstanding, commendable and satisfactory performer would be awarded a performance payment based on the agreed formula.

- $\quad$ The implementation of the policy on appointments, tenure and promotions would allow for structured Job Descriptions, properly set and clearly defined objectives, and structured evaluation of Academic Staff or an on-going supervisory assessment.

\section{Outstanding}

Exceptional performance of unusually high calibre. Remarkable achievement and pace-setting performance. Achievement far exceeds 100\% of targets set for period under review. (A minimum of 120\%).

\section{Commendable}

Performance consistently exceeds what is required to complete assignments or meet standards. Work produced is usually error-free, detailed and clear. Deadlines are usually met before due date. Achievement of 100 $110 \%$ of targets set for period under review.

\section{Satisfactory}

Performance meets acceptable level $95-100 \%$ of objectives. 


\section{Methodology}

A questionnaire was used to capture responses from Academics to determine: the prevalence of performance appraisal especially during the period $2001-2002$, the criteria included in the appraisal process, which factors of the list of six (6) specified should be included in a PBP system and the model of compensation of the three possibilities of (union negotiated increases, annual increments, performance based pay) which should be implemented and the pre-conditions for PBP. One hundred and fifty questionnaires were issued randomly, either directly by the Researcher or through Heads of Schools and through Faculty Administrators. Discussions and telephone interviews were carried out with some Deans and Heads of Schools so as to canvas their views.

\section{Table 1 - Faculty Complement}

\begin{tabular}{|l|c|}
\hline Faculties & 57 \\
\hline Faculty of Health \& Applied Science & 65 \\
\hline Faculty of Education \& Liberal Studies & 64 \\
\hline Business \& Management & 58 \\
\hline Engineering \& Computing & 40 \\
\hline Built Environment & 284 \\
\hline Total & \multicolumn{1}{|c|}{} \\
\hline
\end{tabular}

\section{Results}

Of the one hundred and fifty (150) questionnaires issued ninety seven (97) responses were obtained. The questionnaires were issued by Faculty Administrators and or Senior Administrative persons in the Faculty. Table 2 shows the responses by Faculty.

Table 2 - List Of Faculties And The Number Of Respondents Per Faculty

\begin{tabular}{|l|c|c|}
\hline Faculty & No in Faculty & Number of Responses \\
\hline Health \& Applied & 57 & 23 \\
\hline Education \& Liberal Studies & 65 & 12 \\
\hline Business \& Mgt & 64 & 32 \\
\hline Engineering \& Computing & 58 & 20 \\
\hline Built Environment & 40 & 10 \\
\hline Total & 284 & 97 \\
\hline
\end{tabular}

Table 3 - Appraisal Period And Number Of Respondents Whose Appraisals Were Conducted During The Period

\begin{tabular}{|l|c|c|}
\hline Year & Frequency & Percentage Completed \\
\hline $1998-1999$ & 2 & 2 \\
\hline $1999-2000$ & 11 & 13 \\
\hline $2000-2001$ & 19 & 22 \\
\hline $2001-2002$ & 56 & 63 \\
\hline Total & 88 & 100 \\
\hline
\end{tabular}

Table 3 shows that $88 \%$ of the 97 respondents had their appraisals completed for the $2001-2002$ period. 
Table 4 - Spread Of Appraisals Conducted And The Percentage Including The Relevant Appraisal Factors

\begin{tabular}{|l|c|}
\hline Factors in the Appraisal & Percentage of Respondents whose Appraisal included those factors \\
\hline Peer Assessment & 46 \\
\hline Student Assessment & 66 \\
\hline Research Achievement & 68 \\
\hline Service to the University & 77 \\
\hline Service to the Community & 69 \\
\hline
\end{tabular}

Most of the respondents who were appraised were appraised along the lines laid down by the University to meet its objectives and to be in line with its strategic objectives as shown in Table 4.

Sixty-five percent $(65 \%)$ of respondents have indicated that should PBP be instituted the factors to the be used for assessment should be:
a. Peer Assessment
b. Research Achievement
c. Service to the University
d. Service to Community

Only $7 \%$ have indicated that student assessment should be included in the appraisal process linked to any proposed implementation of PBP.

Table 5 - Respondents View Of Compensation Model

\begin{tabular}{|l|l|c|}
\hline & Factors to be included in a University Compensation Model & Percentage Responsive \\
\hline a & Union negotiated compensation only & 3 \\
\hline b & Annual increments only & No response \\
\hline c. & Performance Based Pay only & 2 \\
\hline d. & Combination of a \& b & 26 \\
\hline e. & Combination of a \& c & 11 \\
\hline f. & Combination of a, b and c & 58 \\
\hline
\end{tabular}

There is a 58\% support for implementation of a pay structure, which includes Union negotiated increase, annual increments and performance based pay. The analysis however, shows that some components should be in place prior to implementation of PBP. Respondents do not show any inclination to phase out annual increments which is the approach the University had intended to take. There is only a 3\% support for union negotiated increases only. This may be due to the small wage and benefits percentage increase of $3 \%$ over the last three years.

Table 6 shows the factors and/or ingredients which should be in place prior to the implementation of the proposed PBP and the percentage of respondents who support their inclusion.

Table 6 - Respondents View Of The Ingredients To Be In Place Prior To Implementation Of PBP

\begin{tabular}{|l|c|}
\hline Components to be in Place Prior to PBP & Percentage \\
\hline Research funding & 56 \\
\hline Reduced teaching load & 68 \\
\hline Research facilities & 58 \\
\hline Peer reviews & 46 \\
\hline Properly structured Appraisal System & 88 \\
\hline Student Assessment & 28 \\
\hline Clearly defined objectives & 76 \\
\hline
\end{tabular}


An examination of Table 6 shows that the two main areas of emphasis prior to implementation of PBP would be a properly structured appraisal system and clearly defined objectives. Of note is the low level of interest in student assessment being part of the proposed structure.

\section{Discussion}

The literature from the United Kingdom shows that some universities operate PBP for senior staff only. However, 65 per cent of pre-1992 universities currently operate a system of PBP for all academic staff or at least operate systems which "base an element of academic staff payment on their performance". Where "PBP" of some kind is used, there appears to be a big emphasis on individual unconsolidated bonuses derived through forms of peer and colleague assessment (for example, through committees organised in a collegial manner (Hardy, 1991; Rutherford, 1992), staffed by academics and with heads or chairs elected from amongst academic staff). A total of 14 respondents (82 per cent) cited collegial methods of PBP decision-making.

\section{The University of Technology, Jamaica}

In follow up and discussions it was revealed that there would be support for a performance based pay system on the premise that such a system would be implemented after the sign off of a properly structured appraisal system, a method of setting clearly defined objectives and the presence of other resources which are standard in the academic setting which would aid teaching, research and service. It does appear that at the University of Technology, Jamaica the culture of union negotiated salary adjustments and annual increments may be the way to go while working on a cultural shift. Two studies (Scott, 1995) and (Winstanley et al 1995) have shown that in the UK situation unless the academic grasps the concept of reward for performance as is the case in the wider society they may continue to behave and be labeled as Academic Civil Servants.

\section{Conclusion}

As universities face greater restrictions in public funding and administrators seek greater discretion over salary determination, departures from traditional seniority-based compensation systems can be anticipated. Merit pay schemes, however, offer no panacea. While the principle of performance-based pay receives some support, implementation of merit plans has proved more intractable. Their appropriateness will depend upon the capacity to structure a system of monitoring and rewarding faculty output that is inexpensive, perceived by faculty to be "fair," and compatible with the institution's objectives and workplace culture.

The incidence of merit pay plans in Canadian universities reinforces the view that institutions with a greater emphasis upon research relative to teaching, where output is "easier" and less costly to measure, will tend to favour pay-for-performance plans. In contrast, where there is distrust of administrative discretion and pressure from faculty associations for more uniform compensation based upon a definition of satisfactory performance, faculty opposition may dissipate the potential productivity gains. Any change in compensation schemes, therefore, is likely to occur slowly and only in the face of significant resistance.

The University of Technology, Jamaica situation is a case study which needs further research. It may be useful to examine the other local university's stance on this area of research and the Ministry of Education's pronouncements on Performance Based Pay for teachers in the public education system.

There is a need for a new culture, the implementation of a new performance appraisal system and a clearly defined set of objectives in the areas of research, teaching and services to the university and community prior to full implementation of performance based pay.

This is not likely to be a smooth transition. Rutherford (1992) highlights some of the difficulties experienced by heads of schools in the University of Birmingham, the majority of whom wanted to retain a spirit of collegiality, but were struggling to do this as the appraisal system was seen to be acting as a catalyst for increasing tension between the demands of the university and the expectations of their colleagues. 
The compensation model that academics would support at the University of Technology, Jamaica would be a combination of union negotiations, annual increments and performance based pay. Central to this view derived from the research are the findings, that a properly structured appraisal system, clearly defined objectives and reduced teaching load should be the planks on which the performance based pay should rest.

\section{References}

1. Armstrong, M. (1996), Employee Reward, Institute of Personnel and Development, London.

2. Armstrong, M. and Murliss, H. (1991), Reward Management, Kogan Page, London

3. Bergman, J.T., \& Scarpello, V.J., (2001) Compensation Decision Making, Thomas Learning

4. Berg, J. G., (1976) Managing Compensation, Amazon

5. Bright, D. and Williamson, B. (1995), "Managing and rewarding performance", in Warner, D. and Crosthwaite, E. (Eds), Human Resource Management in Higher and Further Education, Society for Research into Higher Education/Open University Press, Buckingham, pp. 70-85.

6. Bryman, A., Haslam, C. and Webb, A. (1994), "Performance appraisal in UK universities: a case of procedural compliance?", Assessment and Evaluation in Higher Education, Vol. 19 No. 3, pp. 175-87.

7. Canadian Association Of University Teachers (CAUT). 1993. Merit Pay File.

8. Committee of Vice Chancellors and Principals (1985), Report of the Steering Committee for Efficiency Studies in Universities. (The Jarratt Report), CVCP, London.

9. Coopers \& Lybrand (1996), Profit Related Pay for Universities, Briefing document for University Personnel Association Delegates to the UPA conference, September, Coopers \& Lybrand, London.

10. Dearing Report (1997), Higher Education in the Learning Society: The Report of the National Committee of Inquiry into Higher Education, HMSO, London.

11. Farnham, D. (1985), "Staffing in higher education: the emerging agenda", Higher Education Review, Vol. 18 No. 1, pp. 43-60.

12. Farnham, D. (1997), "Pay bargaining reform in UK higher education: an employers' agenda or negotiating for change?", Higher Education Review, Vol. 29 No. 2, pp. 44-66.

13. Fitz-Enz, J., \& Davidson, B., (2002) How to Measure Human Resource Management,_McGraw-Hill

14. Hardy, C. (1991), "Pluralism, power and collegiality in universities", Financial Accountability and Management, Vol. 7 No. 3, pp. 127-42.

15. Hamermesh, D. S. 1988. "Salaries: Disciplinary Differences and Rank Injustices." Academe, May-June, 2025 .

16. Hoko, J. A. 1988. "Merit Pay: In Search of the Pedagogical Widget." The Clearing House, Vol. 61, No. 1, 29-31.

17. Johnson, H. G. 1974. "The Current and Prospective State of the Economics." Australian Economic Papers, Vol. 13, 1-27.

18. Keep, E., Storey, J. and Sisson, K. (1996), "Managing the employment relationship in higher education: quo vadis?", in Cuthbert, R. (Ed.), Working in Higher Education, Open University Press/Society for Research in Higher Education, Buckingham.

19. Kessler, I. (1994), "Performance pay", in Sisson, K. (Ed.), Personnel Management: A Comprehensive Guide to Theory and Practice in Britain, Blackwell, Oxford, pp. 465-94.

20. Middlehurst, R. and Elton, L. (1992), "Leadership and management in higher education", Studies in Higher Education, Vol. 17 No. 3, pp. 251-63.

21. Miller, H. (1994), The Management of Change in Universities, Open University Press/Society for Research into Higher Education, Buckingham.

22. Murlis, H. and Hartle, F. (1996), "Does it pay to work in universities?", in Cuthbert, R. (Ed.), Working in Higher Education, Open University Press/Society for Research in Higher Education, Buckingham, pp. 46-57.

23. Ontario Confederation Of University Faculty Associations (OCUFA). 1978. Salary and Benefits Working Papers, 1979-80. Toronto. OCUFA. 1980. Merit Pay File.

24. Pratt, L. R. 1988. "Merit Pay: Reaganomics for the Faculty?" Academe, November-- December, 14-16.

25. Prewitt, L. B., Phillips, J. D., and Yasin, K., 1991. "Merit Pay in Academia: Perceptions from the School of Business." Public Personnel Management, Vol. 20, 409-417. 
26. Randell, G. (1994), "Employee appraisal", in Sisson, K. (Ed.), Personnel Management: A Comprehensive Guide to Theory and Practice in Britain, Blackwell, Oxford, pp. 221-52.

27. Rutherford, D. (1988), "Performance appraisal: a survey of academic staff opinion", Studies in Higher Education, Vol. 13 No. 1, pp. 89-100.

28. Rutherford, D. (1992), "Appraisal in action: a case study of innovation and leadership", Studies in Higher Education, Vol. 17 No. 2, pp. 201-10.

29. Scott, P. (1995), The Meanings of Mass Higher Education, Society for Research in Higher Education/Open University Press, Buckingham

30. Taylor, R. L., Hunnicutt, G. G. and Keeffe, M. J. 1991. "Merit Pay in Academia: Historical Perspectives and Contemporary Perceptions." Review of Public Personnel Administration, Vol. II, No. 3, 51-65.

31. Townley, B. (1990), "The politics of appraisal: lessons of the introduction of appraisal into UK universities", Human Resource Management Journal, Vol. 1 No. 1, pp. 27-44.

32. UNIVERSITY OF ALBERTA. Agreement Review Committee. 1991. "An Alternative System of Career Progress and Evaluation of Performance for Faculty: Principles for Consideration."

33. Williams, H. (2001) Implementation of a Performance Based Pay and Incentive System for the University of Technology, Jamaica; submitted to the University Authorities

34. Wilson, T. (1991), "The Proletarianisation of Academic Labour', Industrial Relations Journal, Vol. 22 No. 4, pp. 250-62.

35. Winstanley, D., Sorabji, D. and Dawson, S. (1995), "When the pieces don't fit: a stakeholder power matrix to analyse public sector restructuring", Public Money and Management, Vol. 15 No. 2, pp. 19-26. 